\title{
ERME Column
}

Jason Cooper (Weizmann Institute of Science, Israel)

\section{ERME topic conferences}

European Society for Research in Mathematics Education (ERME) Topic Conferences (ETC) are organised on a specific research theme or themes related to the work of thematic working groups at CERME conferences. Their aim is to extend the work of the group or groups in specific directions, with clear value to the mathematics education research community. We announce an upcoming ETC:

\section{INDRUM - International Network for Didactic Research in University Mathematics}

INDRUM2020, to be held 27-29 March in Bizerte, Tunisia, is the third conference of the International Network for Didactic Research in University Mathematics. Initiated by an international team of researchers in didactics of mathematics, INDRUM aims to contribute to the development of research in didactics of mathematics at all levels of tertiary education, with particular concern for the development of new researchers in the field and for dialogue with mathematicians (https://hal.archives-ouvertes. fr/INDRUM). The themes addressed at INDRUM2020 cover teacher and student practices and the teaching and learning of specific mathematical topics at undergraduate and post-graduate level, as well as across disciplines. The target audience of the conference is researchers in didactics of mathematics, but also mathematicians, teachers and researchers who are interested in these issues. The programme of the conference comprises: a plenary talk by Carl Winsl $\varnothing w$ (University of Copenhagen, Denmark); an expert panel discussion on higher education in the "digital age"; four thematic working groups; short communications in parallel; a poster exhibition; and a training session for young researchers. The main language of the conference is English, with an option of presenting a paper in French or Arabic, provided slides or a handout in English are provided. INDRUM2020 is an ERME topic conference. The event will be preceded on 26 March by a special day in honour of Viviane Durand-Guerrier, who is a former ERME President (2013-2017). For more information see: https://indrum2020.sciencesconf.org.

Thomas Hausberger (INDRUM2020 IPC Chair), Marianna Bosch (IPC Co-chair)

\section{CERME Thematic Working Groups}

The European Society for Research in Mathematics Education (ERME) holds a bi-yearly conference (CERME), in which research is presented and discussed in Thematic Working Groups (TWG). The initiative of introducing the working groups, which we began in the September 2017 issue, will continue in the following issue of the newsletter.

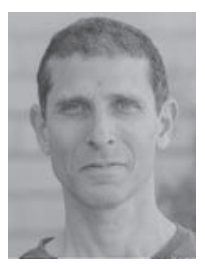

Jason Cooper is an associate staff scientist at the Weizmann Institute's Department of Science Teaching. His research concerns various aspects of teacher knowledge, including roles of advanced mathematical knowledge in teaching mathematics and contributions of research mathematicians to the professional development of mathematics teachers. 